\title{
Transformation of Primary Conjunctival Cells Transfected with Papilloma and Herpesvirus Oncogenes
}

\author{
Kenneth O. Simbiri ${ }^{1,4}$, Hem C. Jha $^{2}$, Giacomina Massaro-Giordano ${ }^{3}$, \& Erle S. Robertson ${ }^{2}$ \\ ${ }^{1}$ Sbarro Institute for Cancer Research and Molecular Medicine \& Center for Biotechnology, Temple University \\ BioLife Science Bldg. Suite 431, 1900 N 12th Street Philadelphia PA 19122, USA \\ ${ }^{2}$ Department of Microbiology, Abramson Cancer Center, Tumor Virology Program, Perelman School of \\ Medicine at the University of Pennsylvania, 202A Johnson Pavilion, 3610 Hamilton Walk, Philadelphia, PA \\ 19104-6076, USA \\ ${ }^{3}$ Department of Ophthalmology, Perelman School of Medicine at the University of Pennsylvania, 51N. 39 ${ }^{\text {th }}$ \\ Street, Philadelphia, PA 19104, USA \\ ${ }^{4}$ Jaramogi Oginga Odinga University of Science and Technology, Bondo, Kenya \\ Correspondence: Sbarro Institute for Cancer Research and Molecular Medicine \& Center for Biotechnology, \\ Temple University BioLife Science Bldg. Suite 431, 1900 N 12th Street Philadelphia PA 19122, USA. E-mail: \\ kenneth.oa.simbiri@temple.edu
}

Received: May 9, $2016 \quad$ Accepted: May 24, $2016 \quad$ Online Published: August 10, 2016

doi:10.5539/cco.v5n2p6 URL: http://dx.doi.org/10.5539/cco.v5n2p6

\begin{abstract}
Ocular surface squamous neoplasia (OSSN) is a common cancer that has recently increased in incidence in HIV-1 infected patients. The rise has been more transparent in sub-Sahara Africa. Our recent publications showed the association of OSSN with multiple viral, bacterial and parasitic infections. Here we show through transfection with different viral constructs, the changes taking place in the primary conjunctival cells which involve some of the important markers associated with initiation and maintenance of the cancer.

We transfected primary conjunctival cells with different oncogenic viral genes (HPV16-E6, HPV16-E7, HPV16-E6/E7, KSHV-LANA, and EBV-EBNA1) that have been associated with transformation of infected cells. The cells were tested for expression of different markers linked to oncogenesis. We used RT PCR to determine the expression of the markers. The level of expression was determined in each case. We also performed immunohistochemistry (IHC) on the primary cells using specific antibodies.

The transfected conjunctival cells were demonstrated to be epitheliod as determined by expression of Cytokeratin-19 (C-19) and Vimentin markers. The primary conjunctival cells were efficiently transfected with the specific viral oncogenes resulting in expression of different cytokines, chemokine, cell cycle markers, and growth factors. The different constructs elicited expression and/or suppression of p53, p21, pRB, IL-10, IL-13, cyclinD1, TNF, TNF13B, and VEGF in specific transfected conjunctival primary cells.

Our findings indicate that the viral oncogene expression in primary conjunctival cells contributed to the production of inflammatory cytokines, chemokines and dysregulation of cell cycle proteins in primary conjunctival tissues. This mirrors the transformation process in OSSN pathogenesis. Further studies should follow to identify pathways dysregulated that can be targeted for therapy or vaccine development.
\end{abstract}

Keywords: primary conjunctival cells, transfection, OSSN, EBV, HPV, KSHV

\section{Introduction}

It has been reported that approximately $20 \%$ of cancers can be attributed to infectious agents such as Helicobacter pylori (HP), Epstein Barr virus (EBV), Kaposi sarcoma-associated herpesvirus (KSHV), Human papilloma virus (HPV), Hepatitis B (HBV) and C (HCV) viruses. These viruses contribute to stomach cancer, Burkitt's lymphoma, Kaposi's sarcoma, cervical cancer, and liver cancer respectively (Parkin, 2002). Several studies have associated the cancers with these oncogenic viruses (Parkin, 2002; Tesfalul et al, 2014; Gichuhi, Ohnuma, Sagoo, \& Burton, 2014; Gichuhi, Sagoo, Weiss, \& Burton 2013, Simbiri et al., 2010; Risse, Massaro-Giordano, Marshall, Lavker, \& Jensen, 2002). Ocular surface squamous neoplasia (OSSN) and other conjunctival carcinomas are increasing in incidence since the advent of HIV-1/AIDS. We have shown the 
association of OSSN with EBV, KSHV, and HPV infection (Simbiri et al., 2010). In our recent publications, we have also shown the association of OSSN with multiple viral, bacterial, and parasitic infections (Simbiri \& Robertson, 2012).

OSSN is a conjunctival or corneal neoplastic growth that covers simple dysplasia, conjunctival intraepithelial neoplasia (CIN), and invasive squamous cell carcinoma (Maho et al., 2014; Kiire \& Dhillon, 2006). Recent studies have shown strong association of OSSN with the HIV pandemic, and colinearity in incidence with HIV-1 infection has been observed in many cases (Wabinga, Parkin, Wabwire-Mangen, \& Nambooze, 2000; Parkin, Nambooze, Wabwire-Mange \& Wabinga, 2010). Some studies have indicated that preceding the HIV-1 pandemic OSSN predominantly occurred in the elderly for whom it is the third most common oculo-orbital tumor after melanoma and lymphoma (Parkin, Nambooze, Wabwire-Mange \& Wabinga, 2010; de Koning et al., 2008). Other risk factors linked to its pathogenesis have included ultraviolet light B rays (de Koning et al., 2008), mutation of the p53 tumor suppressor gene (Tornesello et al., 2005), immunosuppression in organ transplant recipients (Vajdic et al., 2007), cigarette smoking, and human papillomavirus (HPV) infection (de Koning et al., 2008; McDonnell J, McDonnell P, Mounts Wu, \& Green, 1986). In sub-Sahara Africa, OSSN is increasing in prevalence, aggressiveness, and affects predominantly young people who are HIV-1 positive, a majority of whom are women (Waddell, Downing, Lucas \& Newton, 2006).

Cytokines and chemokines are significant factors in innate immunity, apoptosis, angiogenesis, cell growth, and differentiation (Chopra, Dinh \& Hannigan, 1998). They are involved in a vast array of diseases including cancer, and can enhance or modulate these processes by their inflammatory activities (Chopra, Dinh \& Hannigan, 1998). Inflammatory cytokines and chemokines such as tumor necrosis factor alpha (TNF- $\alpha$ ), transforming growth factor beta (TGF- $\beta$ ), interferon gamma (IFN- $\gamma$ ), interleukin 1 beta (IL-1 $\beta$ ), interleukin 6 (IL-6), and interleukin 8 (IL-8) were shown to be involved in inflammatory activities associated with development of HPV linked cancers (Chopra, Dinh \& Hannigan, 1998).

Studies with cervical cancer have shown an increased level of IL-1 $\beta$, IL-6, IL-8, IL-10, TNF- $\alpha$, IFN- $\alpha$, and $\beta$, that are believed to enhance pathogenicity associated with HPV in cervical cancer (Mindiola et al., 2008; Gasperini, Sakakibara \& Tosato, 2008). Similar findings have also been noted with Kaposi's sarcoma (Samanta, Iwakiri \& Takada, 2008), and Burkitt's lymphoma ( Aggarwal, 2003). TNF has been shown to be involved in dysregulation of a number of major signaling pathways important for development of cancer when secreted into the circulation (Woodworth, McMullin, Iglesias \& Plowman, 1995). IL-1, IL-6, IL-8, and IL-18 can mediate different pathways that lead to cancer. For example IL-1 promotes cervical cancer growth (Aggarwal, 2003) while IL-6 is a paracrine growth factor for non-Hodgkin's lymphoma (Klein et al., 1989).

Chemokines such as stromal cell derived factor 1 alpha (SDF-1 $\alpha$ ) and macrophage inflammatory protein 3 alpha (MIP-3 $\alpha$ ) are involved in cancer progression, including angiogenesis, inflammation, cell recruitment, migration, and in recruitment and guiding of leukocytes to sites of inflammation (Charo \& Ransohoff, 2006).

The identification of the oncogenic viruses; HPV, KSHV, and EBV in OSSN tissue samples suggest that these biological cofactors may be involved in the development of this malignancy in the HIV population by partly eliciting the activities of cytokines, chemokines, and growth factors expressed or recruited by cancer cells required for proliferation (Simbiri et al., 2010).

Based on these findings and other studies (Kiire \& Dhillon, 2006; Basti \& Macsai, 2003), our aim in this study was to use primary conjunctival cells transfected with specific oncogenic DNA constructs to investigate if these cells are transformed and indeed express specific factors associated with oncogenesis.

\section{Materials and Methods}

\subsection{Initiating Primary Conjunctival Cells}

We obtained fresh conjunctival biopsies from patients undergoing routine cataract surgery after they signed a written consent approved by the University of Pennsylvania Institutional Review Board (IRB protocol \# 805049). The University of Pennsylvania IRB committee approved the study and consent procedure. The study followed the tenets of the Declaration of Helsinki adhering to informed consent from the subjects. The biopsies were retrieved by sticking the tissues on a socked WECK CEL (Beaver-Visitec International, Inc, Walthan, MA) sponge which was then placed in a sterile container with 2-3ml Balanced Salt Solution (BSS) Sterile Irrigating Solution (Alcon Laboratories, Inc. Forth Worth, Texas). One ml of Hank's Balanced Salt Solution (HBSS) (Gibco Inc., Grand Island, NY) without $\mathrm{Ca}^{2+} / \mathrm{Mg}^{2+}+25 \%$ dialyzed fetal calf serum (FBS) (Hyclone Inc., Logan, UT) was added into a $35 \mathrm{~mm}$ petri dish and brought to room temperature. In a $60 \mathrm{~mm}$ petri dish covered with $25 \%$ HBSS the tissue was placed stroma side down and cut using a rocking motion into smaller portions $(1 \mathrm{x} 1 \mathrm{~mm}$ in 
size) by using forceps and scalpel. The $1 \mathrm{ml}$ HBSS $+25 \%$ FBS was removed and the tissues layered with the stroma side down in the $35 \mathrm{~mm}$ petri dish. We carefully added $300-500 \mu 1$ of Molecular Cellular and Developmental Biology (MCDB) medium (Sigma, St Louis Inc., MO) with $1 \mathrm{mM} \mathrm{Ca}{ }^{2+}$ and $10 \%$ dialyzed FBS around the tissue pieces. The plates were incubated at $37^{\circ} \mathrm{C}$ and $5 \% \mathrm{CO}_{2}$ for $2-3$ days while keeping them moist by adding additional media. Migratory fronts began to appear and once migratory fronts were established on most tissues, the media was changed to Dulbecco's Modified Eagle's Medium (DMEM) (Gibco Inc., Grand Island, NY), 1\% Pen/Strep (Gibco Inc., Grand Island, NY) and 10\% FBS. When the tissue growth reached 80\% confluency they were trypsinized (Trypsin, $0.5 \%$ trypsin/5.3mM EDTA Gibco Inc., Grand Island, NY) and set in T-25 or T-75 tissue culture flasks containing 3-8 $\mathrm{ml}$ of media (Risse, Massaro-Giordano, Marshall, Lavker, \& Jensen, 2002).

\subsection{Transfecting Primary Conjunctival Cells}

Primary conjunctival cells were grown in T-150 flasks to $90 \%$ confluency. $2-3$ million cells in 10ml DMEM+ $10 \%$ FBS were plated in $100 \mathrm{~mm}$ petri dishes and grown overnight. When the cells reached $>70 \%$ confluency the cells were transfected.

All the samples and reagents were brought to room temperature. Into each plate with an 80-90\% confluence, the media was removed and replaced with $10 \mathrm{ml} \mathrm{10 \%} \mathrm{FBS} \mathrm{DMEM.} \mathrm{Master} \mathrm{transfection} \mathrm{media} \mathrm{containing} \mathrm{HIV-Rev}$ protein (Rev), HIV gag-pol protein (Gp) and vesicular stomatitis virus G glycoprotein (VSVG) that have been shown to increase transfection efficiency were applied to the plates. Purified DNA of expression constructs Latency associated nuclear antigen (KSHV-LANA) $(1.0 \mu \mathrm{g} / \mu \mathrm{l})$, Epstein-Barr nuclear antigen 1 (EBV-EBNA1) $(0.5 \mu \mathrm{g} / \mu \mathrm{l}), \mathrm{HPV} 16$-E6/E7 $(1.0 \mu \mathrm{g} / \mu \mathrm{l}), \mathrm{HPV} 16-\mathrm{E} 6(1.0 \mu \mathrm{g} / \mu \mathrm{l})$, and HPV16-E7 $(1.0 \mu \mathrm{g} / \mu \mathrm{l})$ were then added to each specific plate and the volume brought up to $500 \mu \mathrm{l}$ with $\mathrm{H}_{2} \mathrm{O}$ (autoclaved and .22 filter sterilized). $2 \mathrm{M} \mathrm{CaCl}_{2}$ and 2X HEPES-buffered saline (HBS) was added slowly to each sample and incubated for 30min at RT to precipitate the DNA. Five minutes prior to transfection $6 \mu 1$ of $50 \mathrm{mM}$ Chloroquine was added into each plate and uniformly mixed. After the samples were added into specific plates they were incubated for no more than 24 hours due to Chloroquine cytotoxicity. The transfected primary conjunctival cells were monitored for transfection efficiency by Green fluorescent protein (GFP) under immunofluorescence microscopy. The transfection efficiency was over $50 \%$ (Figure 3). The confluent cells were trypsinized, grown in T-75 flasks with several passages. The cells were frozen at $-80^{\mathrm{c}}$ and $-140^{\mathrm{c}}$ until experimentation.

\subsection{Quantitative Real Time-PCR}

RNA was extracted from primary conjunctival cells, transfected primary conjunctival cells and cell line controls, and cDNA prepared accordingly (Applied Biosystems Inc., Foster City, CA). Expressions of cytokines, chemokines, and growth factors were determined by RT-PCR using a Step One Plus Real Time PCR System (Applied Biosystems Inc., Foster City, CA). The cDNA was DNase treated, amplified using Power SYBR green PCR master mix (Applied Biosystems Inc., Foster City, CA), each primer designed across exons (Table 1). Thirty-five cycles of PCR ( 1 cycle consisting of $1 \mathrm{~min}$ at $94^{\circ} \mathrm{C}, 30 \mathrm{~s}$ at $48^{\circ} \mathrm{C}$ to $62^{\circ} \mathrm{C}$, depending on the primer, and $40 \mathrm{~s}$ at $72^{\circ} \mathrm{C}$ ), followed by $60 \mathrm{~s}$ at $72^{\circ} \mathrm{C}$. Relative quantitation was calculated by the $\Delta \Delta \mathrm{Ct}$ method (Cai, Verma, Choi, Ma, \& Robertson, 2010). All experiments were performed in triplicate.

Table 1. Primers used in RT-PCR.

\begin{tabular}{lll}
\hline Gene & Type & Sequence \\
\hline TNF13B & FP & 5'-TACGCCATGGGACATCTAATTCAGA-3' \\
& RP & 5'-GTTTCAGGCATATTTTGAATAC-3' \\
TNF & FP & 5'-CACCCATGTGCTCCTCACCCA-3' \\
& RP & 5'-AGATAGATGGGCTCATAC-3' \\
IL-10 & FP & 5'-TGTCATCGATTTCTTCCCTGTGA-3' \\
& RP & 5'-TCTCTTGGAGCTTATTAAAGGC-3' \\
Il-13 & FP & 5'-AGAAGGCTCCGCTCTGCAAT-3' \\
& RP & 5'-AAAACTGCCCAGCTGAGACCTTG-3' \\
VEGF & FP & 5'-ACATCACCCATCCCACTC-3' \\
& RP & 5'-ACATCACCCATCCCACTC-3' \\
p53 & FP & 5'-GCTCGACGCTAGGATCTGAC-3' \\
& RP & 5'-GCTTTCCACGACGGTGAC-3' \\
pRB & FP & 5'-CCTTCTCGGTCCTTTGATTG-3' \\
& RP & 5'-CAGAAGGCAACTTGACAAGAGA-3' \\
CyclinD1 & FP & 5'-TGCCCTCTGTGCCACAGATG-3' \\
& RP & 5'-TCTGGAGAGGAAGCGTGTG-3' \\
p21 & FP & 5'-GTTCCTTGTGGAGCCGGAGC-3' \\
& RP & 5'-GGTACAA GACAGTGACAGGTC-3' \\
\hline
\end{tabular}


The table shows the list of specific primer sequences used in the quantitative Real Time-PCR experiments. Thirty-five cycles of PCR ( 1 cycle consisting of $1 \mathrm{~min}$ at $94^{\circ} \mathrm{C}, 30 \mathrm{~s}$ at $48^{\circ} \mathrm{C}$ to $62^{\circ} \mathrm{C}$, depending on the primer, and $40 \mathrm{~s}$ at $72^{\circ} \mathrm{C}$ ), followed by $60 \mathrm{~s}$ at $72^{\circ} \mathrm{C}$. Ct values for the relative quantitation were calculated by the $\Delta \Delta \mathrm{Ct}$ method. Transcript quantification results were again normalized against GAPDH DNA content. The experiments were performed in triplicate.

\subsection{Immunocytochemistry}

Initially in this study we needed to verify that the cells we isolated and used in the experiments were of keratinocyte conjunctival cell lineage that have been associated with OSSN. Therefore we screened for specific markers using commercial antibodies for cytokeratin-19 (C-19) (Auw-Haedrich et al., 2011; Rosellini, Papini, Giannarini, Nardi \& Revoltella, 2007; Baudouin, Brignole, Pisella, Becquet \& Philip, 1997),(ABCAM, MA), and vimentin (Baudouin, Brignole, Pisella, Becquet \& Philip, 1997; Garcia-Posadas, Arranz-Valsero, Lopez-Garcia, Soriano-Romani \& Diebold, 2013) (ABCAM, MA), markers for keratinocytes that are widely distributed in these cell types according to the product protocols (Auw-Haedrich et al., 2011; Rosellini, Papini, Giannarini, Nardi \& Revoltella, 2007; Baudouin, Brignole, Pisella, Becquet \& Philip, 1997).

\subsection{Data Analysis}

In this study we had the data collected in Excel and imported into a statistical software program for analysis which encompassed determination of proportions (MedCalc Software bvba MedCalc Software, Ostend, Belgium).

\section{Results}

We investigated the effects of plasmid constructs from identified oncogenic viruses on reproducing results in primary conjunctival cells similar to that seen in OSSN pathogenesis. We obtained conjunctival tissues from adults visiting an eye clinic and generated primary conjunctival cells from the tissues obtained.

\subsection{Primary Conjunctival Cells are of Keratinocyte Lineage}

Each of the initiated primary cells was screened for markers associated with conjunctival cells. University of Pennsylvania Institutional review board approved the study (protocol \# 805049). The study complies with the declaration of Helsinki and consent was obtained from participants. Our results showed that the primary conjunctival cells were of keratinocyte lineage being positive for both cytokeratin-19 and vimentin (Figure $1 \&$ 2).

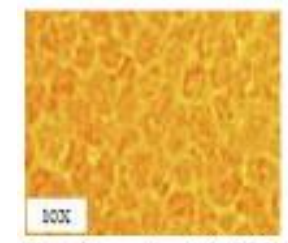

Cytokeratin $19 \mathrm{NC}$

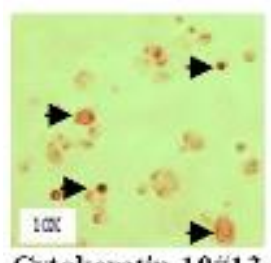

Cytokeratin-19+13
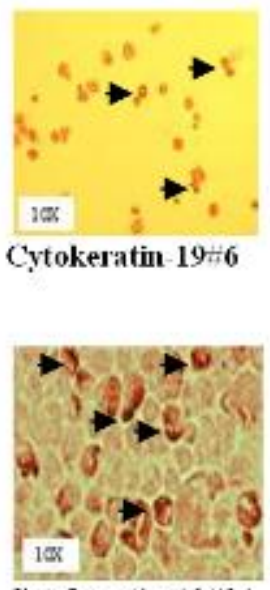

Cytokeratin-19+21
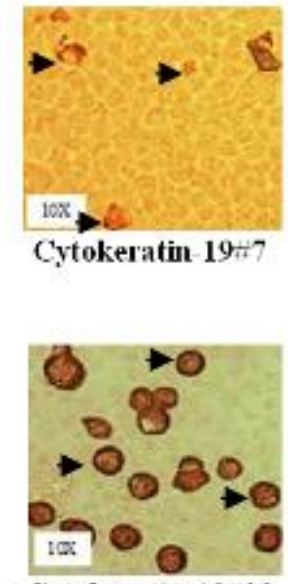

Cytokeratin-19+22

Figure 1. Shows representative primary conjunctival cells stained with antibody against Cytokeratin- 19 with the brown staining showing the presence of the marker (NC-Negative control). 


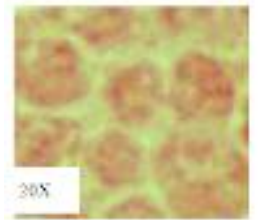

Vimentin \#NC

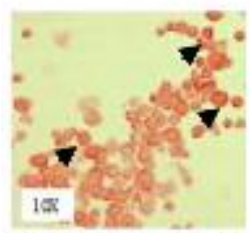

Vimentin \#21

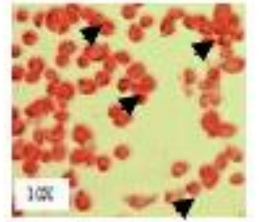

Vimentin \#6

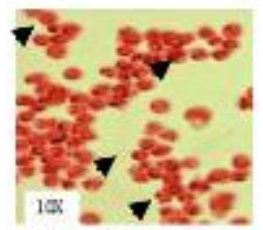

Vimentin \#2

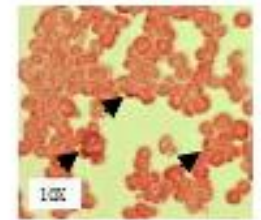

Vimentin \#7

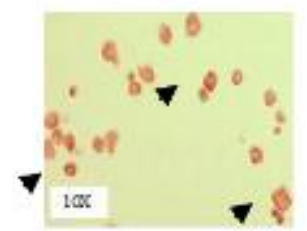

Vimentin \#23

Figure2. Shows the presence of Vimentin marker using anti-Vimentin antibody. We observe the presence of the marker in all the representative cells shown by the brown positive staining (NC-Negative control).

\subsection{The Primary Conjunctival Cells were Efficiently Transfected}

To confirm efficient transfection of the primary cells we utilized GFP transfection of 293-cell line and LVX-GFP-C1 transfection as positive controls, and primary conjunctival cells without any construct DNA (empty vector) and VSVG as negative controls. We observed robust transfection efficiency in the 293-cell line positive control and LVX-GFP-C1 control compared to primary conjunctival cell samples transfected with the oncogenic constructs that nevertheless were still greater than $70 \%$ and was reproducible in multiple transfections (Figure 3A-E, 4A-F).

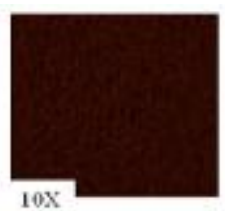

A.
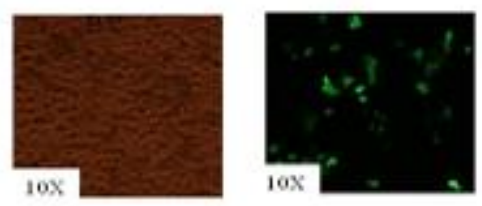

C.
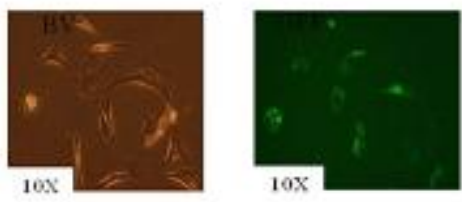

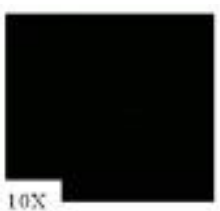

B.
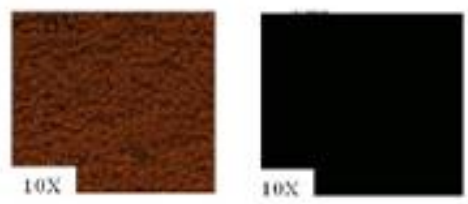

D.

E.

Figure3. Shows the strong GFP fluorescence of the LVX-GFP-C1 positive control; 3B shows the negative GFP fluorescence in the VSVG negative control; 3C shows the GFP fluorescence in the positive GFP-transfected 293 cell line control; 3D shows 293 cell line negative control; and 3E shows a transfected conjunctival primary cell. 
A

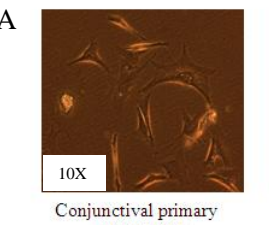

B
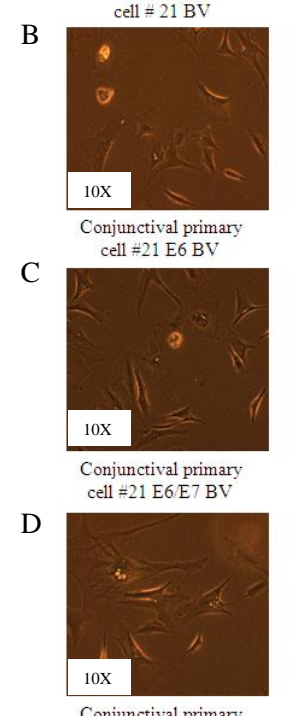

Conjunctival primary

E

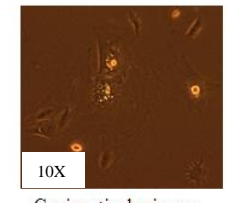

Conjunctival primary

F

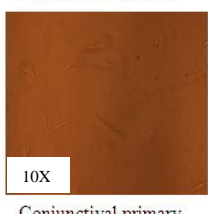

Conjunctival primary

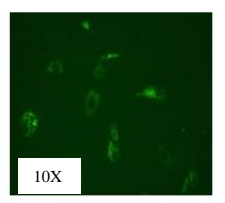

Conjunctival primary

cell $\# 21$ GFP
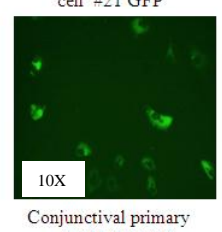

cell $=21$ E6 GFP
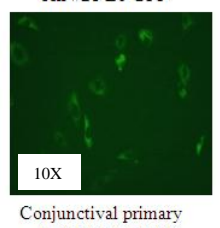

cell $\equiv 21$ E6 E F GFP
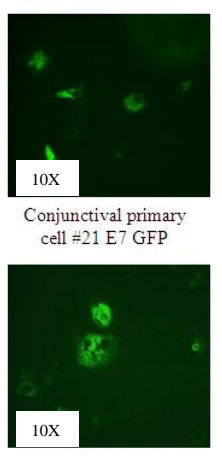

Conjunctival primary cell $\# 21$ EBNA 1 GFP

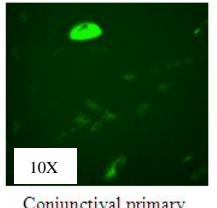

Conjunctival primary
cell $=21$ LANA GFP

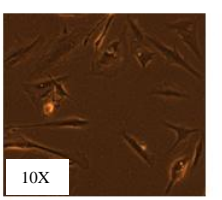

Conjunctival primary cell $\# 23$ BV

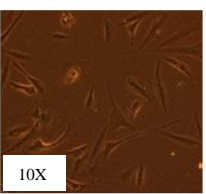

Conjunctival primary cell $\# 23$ E6 BV

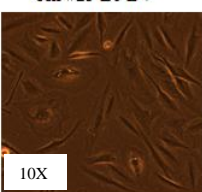

Conjunctival primary cell \#23 E6/E7 BV

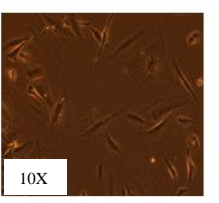

Conjunctival primary cell $\# 23$ E7 BV

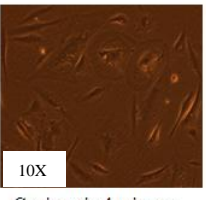

Conjunctival primary cell $=23$ EBNA $1 \mathrm{BV}$

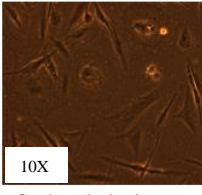

Conjunctival primary cell $=23$ LANA BV

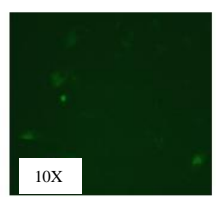

Conjunctival primary cell $\# 23$ GFP

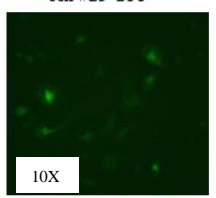

Conjunctival primary cell $=23$ E6 GFP

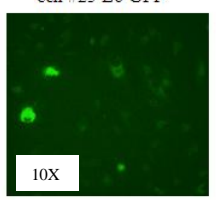

Conjunctival primary cell $=23$ E6 E 7 GFP

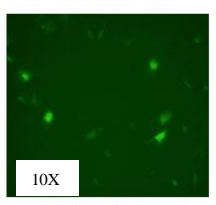

Conjunctival primary cell $\# 23$ E7 GFP

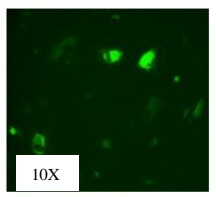

Conjunctival primary cell $\# 23$ EBNA1 GFP

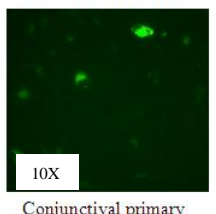

Conjunctival primary
cell $=23$ LANA GFP

Figure 4. Shows primary conjunctival cells transfected with different plasmids.

In each figure we show the bright field sections observed in the transfectants and the bright field section merged with GFP, clearly showing localization of GFP in the transfected cells; 4A-GFP; 4B- HPV16-E6-GFP; 4CHPV16-E6/E7-GFP; 4D- HPV16-E7-GFP; 4E EBNA1-GFP; and 4F-KSHV-LANA-GFP.

\subsection{We were Able to Efficiently Transfect the Primary Conjunctival Cells with the Oncogenic Viral Genes}

Having shown that we could efficiently transfect the primary conjunctival cells with GFP we preceded to transfect the cells with different viral oncogenic plasmids. We observed efficient transfection of the primary cells (Figures 4A-F) showing the bright light and fluorescent component of the same cells. We have used two representative primary conjunctival cells (Case \#21 and \#23) for these figures. Among the many samples initiated some were more robust and more stable through the several passages, \#21 and \#23 are representative of the samples under this category and were thus used for the experiments. On the whole transfection efficiency was similar for all plasmids, with minor differences that was likely due to the specific plasmid and specific subject tissue.

\subsection{The Transfected Primary Conjunctival Cells Elicited the Production of Cytokines and Chemokines}

We showed that the papilloma and herpesvirus constructs could elicit the production and dysregulation of cytokines, chemokines, and cell cycle factors that are associated with initiation and maintenance of the cancer by independently transfecting naïve primary conjunctival cells with the specific oncogenic plasmids. We noted that for HPV16-E6 (Figure 5A) there was expression of TNF13B, IL-10, and IL-13 in the samples, but especially in 
Case \#23 where TNF13B was expressed 10fold, in Case \#79 where IL-10 was expressed 10fold, and Case \#78 where IL-13 was expressed 10fold over the untransfected primary conjunctival cell controls. In cells transfected with HPV16-E6/E7 (Figure 5B) we observed the expression of TNF13B, IL-10, and IL-13 expression in Cases $\# 23, \# 78$, and \#79, but not at a higher level as was observed for HPV16-E6. For HPV16-E7 (Figure 5C) we detected the expression of IL-10 and IL-13 mainly in samples \#78 and \#79. For EBV-EBNA1 (Figure 5D) interestingly we observed the expression of IL-10, TNF, IL-13, but not TNF13B by the same Cases \#23, \#78, and \#79, but again not to the same level as observed with HPV16-E6. Furthermore, for KSHV-LANA (Figure 5E) we observed the expression of IL-10, IL-13, and TNF13B by Cases \#23, \#78, and \#79, but again not to the same level as with HPV16-E6. It was observed that the different oncogenic constructs expressed similar cytokines and chemokines, albeit to different levels, pointing to significant roles they play in the inflammatory process in OSSN pathogenesis. It was observed that HPV16-E6 that has been shown to be more oncogenic than other HPV oncogenes elicited higher level of the factors. Overall, the differences in levels observed in the expression of these different cytokines/chemokines that have been associated with OSSN, may be due to the individual tissue sample, or oncogene transfected (Table 2).

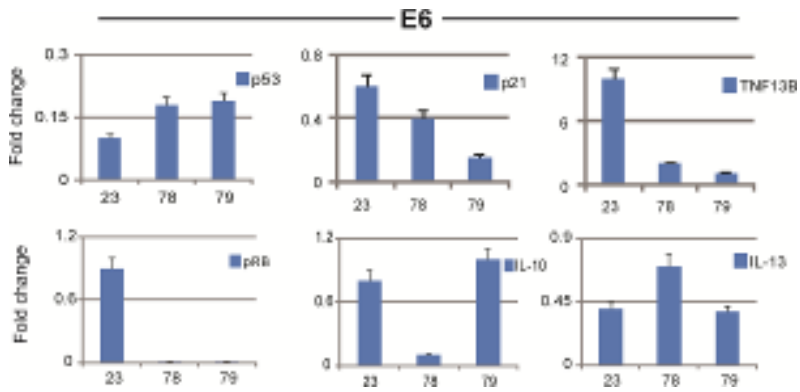

Figure 5A. Shows RT-PCR results of the factors expressed by the HPV16-E6 construct in representative primary conjunctival cells.

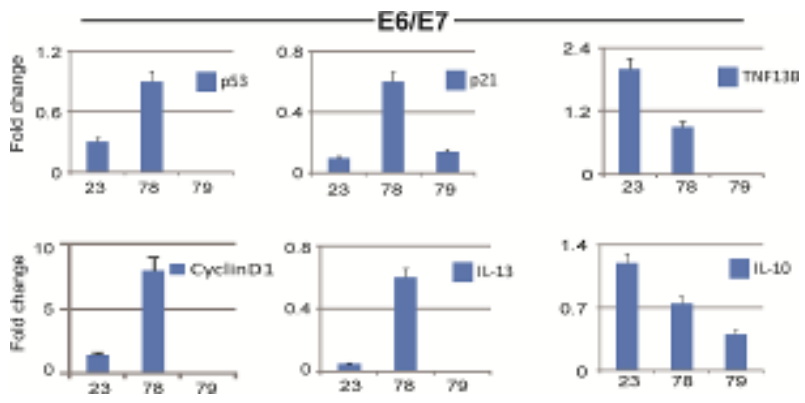

Figure 5B. Shows RT-PCR observation of the factors expressed by HPV16-E6/E7 in representative primary conjunctival cells.
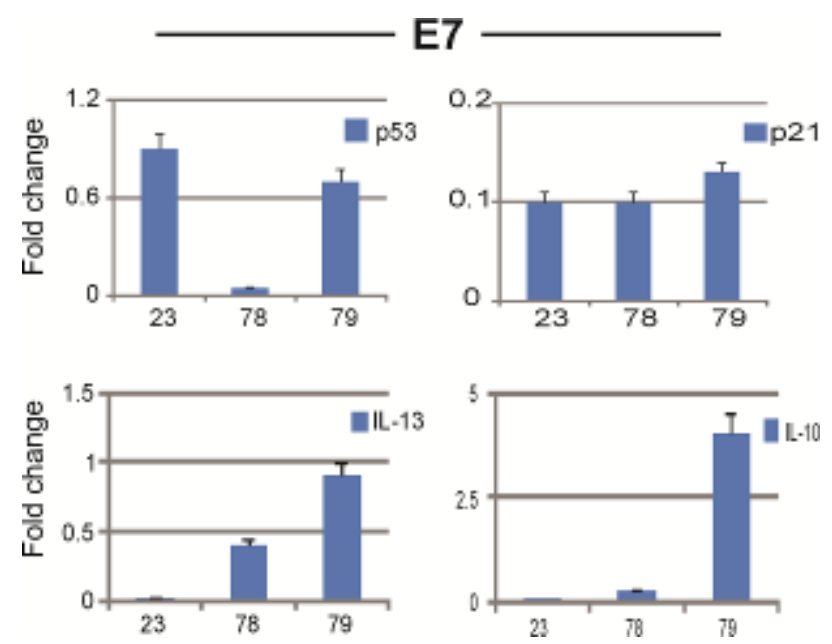

Figure 5C. Shows RT-PCR findings of the factors expressed by HPV16-E7 in representative primary conjunctival cells. 

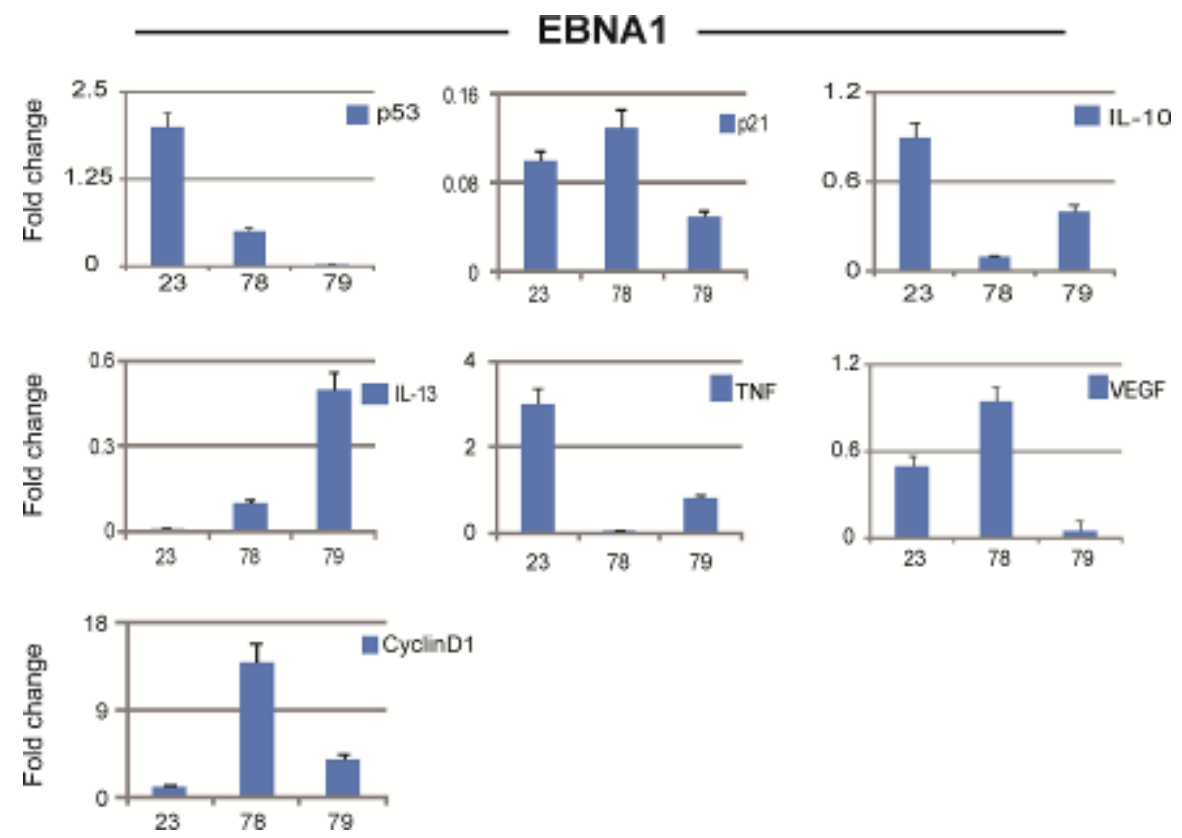

Figure 5D. Shows RT-PCR results of the factors expressed by EBV-EBNA1 in representative primary conjunctival cells.

LANA
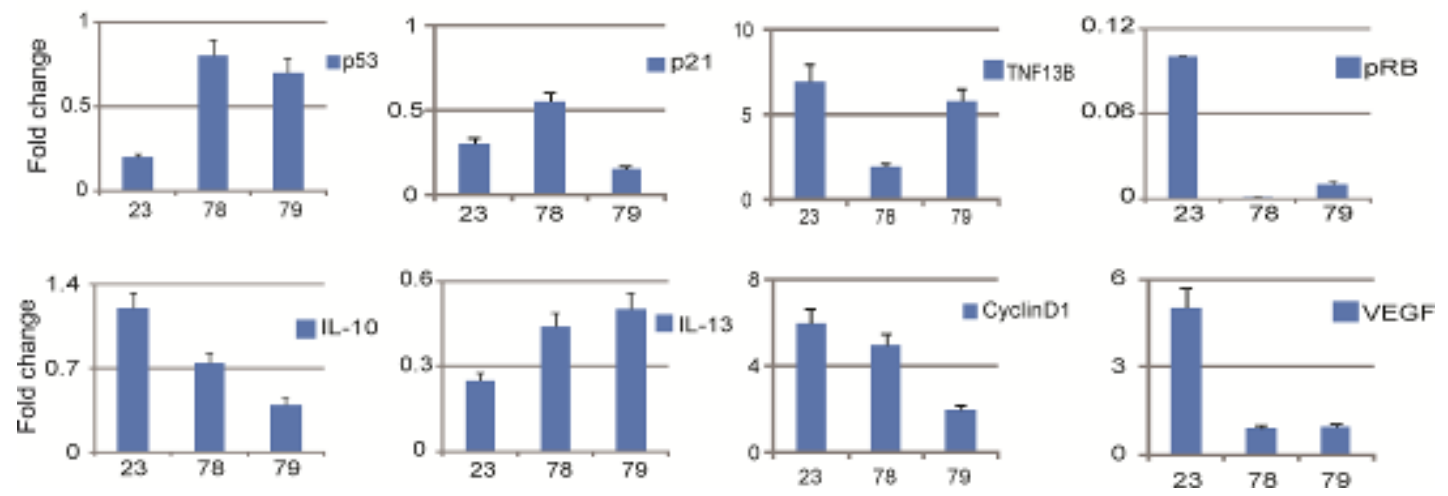

Figure 5E. Shows RT-PCR results of the factors expressed by KSHV-LANA in representative primary conjunctival cells.

\subsection{Cell Cycle Proteins Were Expressed by the Transfected Cells to Appreciable Levels in Different Transfected Primary Conjunctival Cells}

As with the cytokines and chemokines, we similarly investigated the expression of a number of cell cycle proteins that are associated with cancer and observed that expression of the proteins varied between the different plasmid constructs. For cells transfected with HPV16-E6 (Figure 5A) we observed the expression of p21 by Cases \#23, \#78, and \#79. For cells transfected with the combination construct HPV16-E6/E7 (Figure 5B) we likewise observed the expression of $\mathrm{p} 21$ by Cases \#23, \#78, and \#79, and Cyclin D1 by Cases \#23 and \#78. For HPV16-E7 transfected cells (Figure 5C) similarly we observed the expression of p21 by the same Cases \#23, \#78, and \#79.

For the oncogenes encoded by the oncogenic herpesviruses; EBV-EBNA1 (Figure 5D) we observed expression of p21, Cyclin D1, and vascular endothelial growth factor (VEGF) by Cases \#23, \#78, and \#79. Whereas for KSHV-LANA (Figure 5E) we similarly detected the expression of p21, Cyclin D1, and VEGF by Cases \#23, \#78, and \#79. As was noted with cytokines and chemokines the differences in level of expression may be due to the oncogenic plasmid used and specific sample variation (Table 2). 


\subsection{The Tumor Suppressor Proteins P53 and Prb Are Dysregulated in the Primary Conjunctival Cells Expressing Oncogenic Viral Antigens}

The tumor suppressor proteins p53 and retinoblastoma protein (pRB) have been shown to play a significant role in other cancers such as cervical cancer (Chopra, Dinh \& Hannigan, 1998; Mindiola et al., 2008; Garcia-Posadas, Arranz- Valsero, Lopez-Garcia, Soriano-Romani \& Diebold, 2013). We determined the expression of the two proteins in our samples and observed that for HPV16-E6 transfected cells (Figure 5A) p53 was expressed by Cases \#23, \#78, and \#79, while pRB was expressed to an appreciable level by Case \#23 alone. For HPV16-E6/E7 transfected primary cells (Figure 5B) again only p53 was expressed to an appreciable level by Cases \#23 and \#78, pRB was not expressed to a detectable level by any of the samples. For HPV16-E7 (Figure 5C) expression to appreciable level was observed for p53 alone, but not for pRB. For EBV-EBNA1 (Figure 5D) we again observed the expression of p53 alone by Cases \#23 and \#78, and no pRB expression, while for KSHV-LANA (Figure 5E) we observed the expression of p53 by Cases \#23, \#78, and \#79 and pRB by Cases \#23 and \#79, again some of the differences maybe attributable to transfected oncogene or specific sample variances (Table 2).

Table 2. Expression levels of different factors in Cases \#23, \#78, and \#79 transfected with different papilloma and herpesvirus oncogenes.

Case \#23

\begin{tabular}{lllllllllllll}
\hline & & Negative & 293 & P53 & P21 & pRB & Cyc. D1 & TNF & TNF 13B & VEGF & IL-10 & IL-13 \\
\hline Constructs & - & - & & & & & & & & & & \\
E6 & - & - & + & ++ & ++ & - & - & +++ & - & ++ & + \\
E7 & - & - & ++ & + & - & - & - & - & - & - & - \\
C6/E7 & - & - & + & + & - & + & - & ++ & - & ++ & + \\
EBNA1 & - & - & ++ & ++ & - & + & ++ & - & + & ++ & - \\
LANA & - & - & + & + & ++ & ++ & - & ++ & +++ & +++ & + \\
\hline & & & & & & & & & & & & \\
\hline & & Negative & 293 & P53 & P21 & pRB & Cyc. D1 & TNF & TNF 13B & VEGF & IL-10 & IL-13 \\
\hline Constructs & - & - & & & & & & & & & \\
E6 & - & - & ++ & ++ & - & - & - & + & - & + & ++ \\
E7 & - & - & + & + & - & - & - & - & - & + & + \\
E6/E7 & - & - & ++ & ++ & - & +++ & - & ++ & - & + & ++ \\
EBNA1 & - & - & + & +++ & - & +++ & - & - & ++ & + & + \\
LANA & - & - & ++ & ++ & - & ++ & - & + & + & + & ++ \\
\hline & & & & & & & & & & & + \\
\hline
\end{tabular}

This table shows the expression levels of different factors in Cases \#23, \#78, and \#79 transfected with different papilloma and herpesvirus oncogenes. Variance in expression of the measured factors is clearly observed in the three cases.

- = No expression

$+=$ Low expression

$++=$ Moderate expression

$+++=$ High expression

\section{Discussion}

In this study we investigated the effects of transfecting primary conjunctival cells with known oncogenic plasmids on elicitation of factors that have been linked to OSSN pathogenesis in patients. We observed that the different conjunctival samples transfected showed dysregulated expression of inflammatory cytokines/chemokines, growth factors, and tumor suppressors that have been associated with oncogenesis. The levels of expression were generally similar, with minor differences that could be due to variances in samples, which were retrieved from different subjects with diverse immune statuses and ages.

In our studies with the HPV16-E6 construct we observed the expression of tumor suppressors p53 and pRB. 
Studies have indicated that the dysregulation of p53 and pRB affect the transforming ability of tumor cells which may involve adjustment in supply of blood to the transformed cells leading to increased growth and spread ( Hanahan \& Folkman, 1996; Vikhanskaya et al., 2001). This process, called angiogenic switch results in an altered phenotype in which activities of angiogenic inhibitors decrease relative to angiogenic inducers enhancing spread of the tumor such as OSSN, especially in immunocompromised patients (Igarashi, Esumi, Ishida \& Okada, 2002; Gomez-Manzano et al., 2003). The HPV16-E6 transfected cells also expressed TNF13B, IL-10, and IL-13.

When HPV16 infects keratinocytes, one major function of E6 and E7 is to disrupt the activity of two tumor suppressor proteins, p53 and pRB (Munger \& Howley, 2002). This disruption results in dysregulated proliferation and unrestricted cell cycle entry (Munger \& Howley, 2002). Previous studies that examined angiogenesis in cervical cancer have demonstrated that angiogenesis is an early event that becomes evident before malignancy. In both, a transgenic mouse model expressing HPV16 early genes, and in human cervical lesions progressing along the continuum from low-grade dysplasia to invasive carcinoma, studies indicate that angiogenesis occurs in a stepwise manner (Munger \& Howley, 2002, López-Ocejo et al., 2000). With regards to $\mathrm{pRB}$, studies have shown that the convergent evolution of $\mathrm{pRB}$ inhibitory mechanisms by tumor viruses illustrates the importance of the pRB checkpoint to the life cycles of both DNA and RNA tumor viruses. pRB inhibition has been attributed to the need for a virus to induce S-phase DNA synthesis in order to expand virion production (Jansen-Dürr, 1996). This is likely to be the case for at least some tumor viruses such as EBV and KSHV during lytic virus replication. EBV, for example, encodes the lytic replication transactivator proteins (BRLF1 and BZLF1), which directly inhibit the pRB and p53 proteins (Zacny, Wilson \& Pagano, 1998; Zhang, Gutsch \& Kenney, 1994). However, pRB inactivation during virus latency does not preferentially replicate viral genome over host cell genome. An alternative explanation for $\mathrm{pRB}$ inhibition during virus latency is that cell cycle arrest serves as an antiviral mechanism to limit latent virus replication (Moore \& Chang, 1998). Swanton and colleagues have demonstrated that the KSHV vCYC is resistant to cellular CDK inhibitors that control cyclin D activities [Sarid, Flore, Bohenzky, Chang \& Moore, 1998). This suggests that KSHV replaces cellular cyclin D activity with a viral cyclin that is resistant to cellular control mechanisms. In this case, vCyc expression may re-establish cell cycle homeostasis in the presence of active cellular antiviral responses that would otherwise induce cell cycle arrest.

Though our HPV16 construct did not induce VEGF or IL-8 at detectable levels, other studies such as Ravi et al (Ravi et al., 2000) have shown the expression of VEGF and IL-8, both potent inducers of angiogenesis, increased in HPV16-E6 and -E7 expressing keratinocytes, but not in controls (Munger \& Howley, 2002). Additionally, in our studies HPV16-E6/E7 transfected primary cells also expressed TNF13B, IL-10, IL-13, p21 and Cyclin D1, while for HPV16-E7 transfected primary cells alone only p21 was expressed. Interestingly, as shown above the HPV16 oncoproteins E6 and E7 can disrupt the functions of tumor suppressors p53 and pRB, respectively. Lopez-Ocejo et al, have shown that three of the factors whose levels are altered in HPV16-E6 and-E7 expressing cells are regulated by p53 (Lopez-Ocejo et al., 2000). Loss of p53 results in upregulation of VEGF. They however suggest that the regulation of VEGF by HPV16 -E6 can occur via a p53-independent mechanism. In p53-/- mouse embryonic fibroblast cells, HPV16-E6 can activate the VEGF promoter via the Sp-1 transcription factor binding sites. The VEGF promoter also contains an AP-1 site that could potentially be activated by E7 (Tisher et al., 1991; Antinore, Birrer, Patel, Nader \& McCance, 1996). Other studies (Arbeit, Munger, Howley \& Hanahan, 1994; Guidi et al., 1995; Smith-McCune, Zhu, Hanahan \& Arbeit, 1997) have shown that increasing vascular density and increasing expression of the pro-angiogenic factor VEGF correlates with progression toward tumor development. The differences observed in our study and these other studies could be based on our use of primary cells versus cell line based experiments in the studies.

Conjunctival primary cells transfected with the EBV-EBNA1 construct induced the tumor suppressors, cytokines, and cell cycle protein genes. The consistent expression of EBNA1 in all EBV-related malignancies is a result of the indispensable role that EBNA1 plays in maintenance and replication of the EBV genome via sequence-specific binding to the viral origin of replication, oriP (Raab-Traub, 2002). In addition to the role that EBNA1 plays in viral genome maintenance, it also interacts with viral gene promoters, thereby contributing to the transcriptional regulation of the EBNAs and of LMP1. In our studies the EBNA1 transfected primary cells expressed IL-10, TNF, and IL-13, p21, Cyclin D1, p53, and VEGF. Recent studies have also demonstrated that EBNA1 can interact with the ubiquitin-specific protease USP7, which has also been implicated in the stabilization of p53 (Holowaty, \& Frappier, 2004). Holowaty \& Frappier showed that EBNA1 can bind with a higher affinity to the same region of USP7 as p53 and MDM2 and suggest that, as a consequence, EBNA1 can protect against either UV- or p53-induced apoptosis, a factor which is worth investigating in our samples 
(Holowaty, \& Frappier, 2004). O'Neil et al demonstrated by gene expression microarray profiling in an NPC cell model that EBNA1 influences the expression of a range of cellular genes, including those involved in transcription, translation and cell signaling. They showed that EBNA1 enhances activity of the AP-1 transcription factor in NPC cells and demonstrated that this is achieved by EBNA1 binding to the promoters of c-Jun and ATF2, enhancing their expression. They also demonstrated elevated expression of the AP-1 targets interleukin 8, VEGF and hypoxia-inducible factor-1 $\alpha$ (HIF-1 $\alpha)$ in response to EBNA1 expression, which had been shown to enhance microtubule formation in an in vitro angiogenesis assay (O'Neil et al., 2008). Further, Krishna et al have demonstrated strong positive staining for VEGF in a high proportion (50\%) of NPC cases studied. In addition, elevated VEGF expression and secretion were reported to be associated with enhanced angiogenesis and poor prognosis both in NPC cell models and in NPC biopsies (Yoshizaki et al, 2001; Krishna, James \& Balaram, 2006). Moreover, Josko \& Mazurek, 2004 also reported that the regulation of VEGF expression is controlled, at least in part, by AP-1 (Josko, \& Mazurek, 2004).

Latency associated nuclear antigen (LANA) is the dominant protein expressed during KSHV latency and its expression leads to the induction of tumor suppressor p53, pRB, cytokines and chemokines, and other growth factors. In our study the LANA transfected primary cells expressed IL-10, IL-13, TNF13B, p21, Cyclin D1, p53, $\mathrm{pRB}$, and VEGF. LANA controls episomal maintenance and replication by tethering KSHV episome to the chromosome. LANA has been reported to downregulate tumor suppressor pathways regulated by p53 and pRB (Verma, Lan, Robertson, 2007; Sherr \& McCormick, 2002). LANA protein binds to the negative regulator glycogen-synthase kinase-3 (GSK-3), causing a cell cycle-dependent nuclear accumulation of GSK-3, which has been shown to stabilize beta-catenin and increase its levels (Auw-Hadrich, Gobel \& Illerhaus, 2010). Further, LANA has been shown to associate with GSK-3 $\beta$, a modulator of Wnt signaling pathway leading to accumulation of cytoplasmic $\beta$-catenin, which upregulates Tcf/Lef regulated genes after entering into the nucleus (Fujimuro \& Hayward, 2003). Lan et al. have reported that LANA is responsible for maintaining viral episome, inhibiting viral reactivation, and promoting cell proliferation by targeting p53, pRb and GSK-3 $\beta$ (Lan et al, 2007). Lan et al. have also shown that LANA contributes to cell proliferation by promoting intracellular Notch (ICN) accumulation through inhibition of Sel10-mediated ICN degradation, and that LANA can block the expression of RTA (Lan, Kuppers, Verma \& Robertson, 2004; Verma \& Robertson, 2004; Lan et al., 2005b) the replication and transcription activator involved in the latency to lytic switch. We can thus comprehend the possible effects of LANA in OSSN pathogenesis. Its association with the expression of cytokines, growth factors, and tumor suppressors in this study, and likely interaction with other papilloma and herpesvirus oncogenic genes calls for further investigation. The cross-talk between the papilloma and herpesvirus oncogenes is exemplified by the control of Cyclin D1 that is required for progression through G1 cell cycle phase controlled by pRB, but has been shown to be overcome by pRB inactivation by HPV 16 [Jansen-Dürr, 1996], EBV EBNA-LP and EBNA-2 (Hollyoake, Stuhler, Farrell \& Gordon, 1995; Kempkes et al, 1995; Sinclair, Palmero, Peters \& Farrell, 1994), and KSHV, which interestingly has been shown to encode many cellular genes induced by EBV (Moore, Boshoff, Weiss \& Chang, 1996; Moore \& Chang, 1998).

\section{Conclusion}

This study, based on transfection of primary conjunctival cells with a number of oncogenic viral antigens, has shown that induction of cellular factors that are associated with oncogenesis may play a significant role in the onset of OSSN. The transfection efficiency was generally high (>70\%) in most of the cells. We observed varied levels of Vimentin and Cytokeratin 19(C-19) expressing keratinocytes in the tissues which may be a factor influenced by each subject's immune status. The subject variation in the response to the transfected constructs was observed in the expression of the cytokines, chemokines, and growth factors. Expression levels of the different constructs could be due to the level and efficiency of transfection and patient variances that may in turn affect the level of cell cycle proteins and other factors expressed. Cytokines, chemokines, and growth factors elicited during the initiation and maintenance of the cancer may vary with each virus, or the viruses may act synergistically. Of interest would be the investigation of shared pathways by the viruses in these cancer pathogenic processes that may contribute to therapeutic and vaccine development.

The demonstration that active expression of HPV, KSHV, and EBV encoded antigens in vitro in primary conjunctival cells could control the expression of these different cellular factors provides an insight into yet another mechanism through which these viruses could promote malignancies such as OSSN. There is a possibility that the interaction of the different oncogenic viral proteins in vivo may impact the pathogenesis process of OSSN in patients. Some of the interaction may be synergistic and others suppressive in the tissue microenvironment. Some of the observed variance could be due to subject differences in the tissues utilized in the study such as other infections the cases were exposed to prior to extraction of the conjunctival tissues. Thus 
for similar studies in future, besides using primary conjunctival tissue cells, there would be a need for conjunctival cell lines that could be used for an expanded investigation of the significance of these papilloma and herpesvirus oncogenic genes in initiation and maintenance of these malignancies.

\section{Competing Interests}

The authors declare that they have no competing interests.

\section{Acknowledgements}

We would like to extend special thanks to all the patients and the personnel at the Scheie Eye Institute who made this study possible.

\section{Funding}

This work was supported by the Public Health awards from the National Cancer Institute of the National Institutes of Health (CA137894, CA138434, CA72150, CA91792, CA91792-S1, CA91792-S2, CA108461 to ESR); and the National Institute of Allergy and Infectious Diseases (A167037 to ESR).

\section{References}

Aggarwal, B. B. (2003). Signalling pathways of the TNF superfamily: a double-edged sword. Nat Rev Immunol, 3, 745-756. http://doi.org/10.1038/nri1184.

Antinore, M.J., Birrer, M. J., Patel, D., Nader, L., \& McCance, D. J., (1996). The human papillomavirus type 16 E7 gene product interacts with and trans-activates the AP1 family of transcription factors. EMBO J., 15(8), 1950-60.

Arbeit, J. M., Münger, K., Howley, P. M., \& Hanahan, D. (1994). Progressive squamous epithelial neoplasia in K14-human papillomavirus type 16 transgenic mice. J Virol. 68(7), 4358-68.

Auw-Hädrich, C., Göbel, N., \& Illerhaus, G. (2010). Infectious agents in ocular adnexal tumours. Klin Monbl Augenheilkd, 227(7), 530-7. http://doi.org/10.1055/s-0029-1245153.

Auw-Haedrich, C., Agrawal, M., Gabbert, H. E., Meyer, P., Arnold, N., \& Reinhard, T. (2011). Immunohistochemical expression of epithelial cell markers in corneas with congenital aniridia and ocular cicatrizing pemphigoid. Acta Ophthalmol. 89(1), 47-53. http://doi.org/10.1111/j.1755-3768.2009.01603.x.

Basti, S., \& Macsai, M. S. (2003). Ocular surface squamous neoplasia: a review. Cornea, 22, 687-704. http://dx.doi.org/10.1097/00003226-200310000-00015

Baudouin, C., Brignole, F., Pisella, P. J., Becquet, F., \& Philip, P. J. (1997). Immunophenotyping of human dendriform cells from the conjunctival epithelium. Curr Eye Res. 16(5), 475-81. http://dx.doi.org/10.1076/ceyr.16.5.475.7053

Cai, Q, Verma, S. C., Choi, J. Y., Ma M, \& Robertson, E. S. (2010). Kaposi's sarcoma-associated herpesvirus inhibits interleukin-4-mediated STAT6 phosphorylation to regulate apoptosis and maintain latency. $J$ Virol. 84(21), 11134-44. http://doi.org/10.1128/JVI.01293-10.

Charo, I. F., \& Ransohoff, R. M. (2006). The many roles of chemokines and chemokine receptors in inflammation. $N$ Engl J Med, 354, 610-621. http://dx.doi.org/10.1056/NEJMra052723

Chopra, V., Dinh, T. V., \& Hannigan, E. V. (1998). Circulating serum levels of cytokines and angiogenic factors in patients with cervical cancer. Cancer Invest, 16, 152-159. http://dx.doi.org/10.3109/07357909809050029

Fujimuro, M., \& Hayward, S. D. (2003). The latency-associated nuclear antigen of Kaposi's sarcoma-associated herpesvirus manipulates the activity of glycogen synthase kinase-3ß. $J$ Virol. 77, 8019-8030. http://dx.doi.org/10.1128/JVI.77.14.8019-8030.2003

García-Posadas, L., Arranz-Valsero, I., López-García, A., Soriano-Romaní, L., \& Diebold, Y. (2013). A new human primary epithelial cell culture model to study conjunctival inflammation. Invest Ophthalmol Vis Sci. 54(10), 7143-52. http://doi.org/10.1167/iovs.13-12866.

Gasperini, P., Sakakibara, S., \& Tosato, G. (2008). Contribution of viral and cellular cytokines to Kaposi's sarcoma-associated herpesvirus pathogenesis. $J$ Leukoc Biol, 84, 994-1000. http://doi.org/10.1189/jlb.1107777

Gichuhi, S., Ohnuma, S., Sagoo, M. S., \& Burton, M. J. (2014). Pathophysiology of ocular surface squamous neoplasia. Exp Eye Res. Dec, 129, 172-82. http://doi.org/10.1016/j.exer.2014.10.015. Epub 2014 Oct 18.

Gichuhi, S., Sagoo, M. S., Weiss, H. A., \& Burton, M. J. (2013). Epidemiology of ocular surface squamous 
neoplasia in Africa. Trop Med Int Health. Dec, 18(12), 1424-43. http://doi.org/10.1111/tmi.12203.

Gomez-Manzano, C., Fueyo, J., Jiang, H., Glass, T. L., Lee, H. Y., Hu, M., Liu, J. L., Jasti, S. L., Liu, T. J., Conrad, C. A., \& Yung, W. K. (2003). Mechanisms underlying PTEN regulation of vascular endothelial growth factor and angiogenesis. Ann Neurol., 53(1), 109-17. http://dx.doi.org/10.1002/ana.10396

Guidi, A. J., Abu-Jawdeh, G., Berse, B., Jackman, R. W., Tognazzi, K., Dvorak, H. F., \& Brown, L. F. (1995). Vascular permeability factor (vascular endothelial growth factor) expression and angiogenesis in cervical neoplasia. J Natl Cancer Inst, 87(16), 1237-45. http://dx.doi.org/10.1093/jnci/87.16.1237

Hanahan, D., \& Folkman, J. (1996). Patterns and emerging mechanisms of the angiogenic switch during tumorigenesis. Cell. 86(3), 353-64. http://dx.doi.org/10.1016/S0092-8674(00)80108-7

Hollyoake, M., Stuhler, A., Farrell, P., Gordon, J., \& Sinclair, A. (1995). The normal cell cycle activation program is exploited during the infection of quiescent B lymphocytes by Epstein-Barr virus. Cancer Res, 55, 4784-4787.

Holowaty, M. N., \& Frappier, L. (2004). HAUSP/USP7 as an Epstein-Barr virus target. Biochem Soc Trans, 32, 731-732. http://dx.doi.org/10.1042/BST0320731

Igarashi, H., Esumi, M., Ishida, H., \& Okada, K. (2002). Vascular endothelial growth factor overexpression is correlated with von Hippel-Lindau tumor suppressor gene inactivation in patients with sporadic renal cell carcinoma. Cancer, 95(1), 47-53. http://dx.doi.org/10.1002/cncr.10635

Initiation and characterization of keratinocyte cultures from biopsies of normal human conjunctiva. (2002). Exp Eye Res, 74(1), 61-9.

Jansen-Dürr, P. (1996). How viral oncogenes make the cell cycle. Trends Genet, 12, 270-275. http://dx.doi.org/10.1016/0168-9525(96)81455-7

Josko, J., \& Mazurek, M. (2004). Transcription factors having impact on vascular endothelial growth factor (VEGF) gene expression in angiogenesis. Med Sci Monit, 10, RA89-RA98.

Kempkes, B., Spitkovsky, D., Jansen-Dürr, P., Ellwart, J. W., Kremmer, E., Rottenberger, C., \& Bornkamm, G. W. (1995). Hammerschmidt W. B-cell proliferation and induction of early $\mathrm{G}_{1}$-regulating proteins by Epstein-Barr virus mutants conditional for EBNA2. EMBO J., 14, 88-96.

Kenneth, O., S., \& Erle, S. R. (2012). Characterization of the OSSN Microbiome in HIV-1 Infected Patients. Cancer and Clinical Oncology, 1(1), 88-101.

Kenneth, O. S., Hem, C. J., \& Richard, D. D., (2012). Giacomina Massaro-Giordano, Erle S Robertson. Cytokine and Chemokine Expression Profiles in HIV-1 Infected Patients with Ocular Surface Squamous Neoplasia from Botswana. Cancer and Clinical Oncology, 1(2), 10-24.

Kenneth, O. S., Masanao, M., \& Michael, F., \& Andrew, S. (2010). Oathokwa Nkomazana, Gregory Bisson, \& Erle S Robertson. Multiple oncogenic viruses identified in ocular surface squamous neoplasia in HIV-1 patients. Infectious Agents and Cancer, 5, 6-26. http://dx.doi.org/10.1186/1750-9378-5-6

Kiire, C. A., \& Dhillon, B. (2006). The aetiology and associations of conjunctival intraepithelial neoplasia. $B r J$ Ophthalmol, 90, 109-13. http://dx.doi.org/10.1136/bjo.2005.077305

Klein, B., Zhang, X. G., Jourdan, M., Content, J., \& Houssiau, F., et al. (1989). Paracrine rather than autocrine regulation of myeloma-cell growth and differentiation by interleukin-6. Blood, 73, 517-526.

de Koning, M. N, Waddell, K., Magyezi, J., Purdie, K., Proby, C., Harwood, C., Lucas, S., \& Downing, R., (2008). Quint WG, Newton R. Genital and cutaneous human papillomavirus (HPV) types in relation to conjunctival squamous cell neoplasia: a case-control study in Uganda. Infect Agent Cancer, 3, 12. http://doi.org/10.1186/1750-9378-3-12.

Krishna, S. M., James, S., \& Balaram, P. (2006). Expression of VEGF as prognosticator in primary nasopharyngeal cancer and its relation to EBV status. Virus Res, 115, 85-90. http://dx.doi.org/10.1016/j.virusres.2005.07.010

Lan, K., Kuppers, D. A., Verma, S. C., \& Robertson, E. S. (2004). Kaposi's sarcoma-associated herpesvirus-encoded latency-associated nuclear antigen inhibits lytic replication by targeting Rta: a potential mechanism for virus-mediated control of latency. $J$ Virol, $78, \quad 6585-6594$. http://dx.doi.org/10.1128/JVI.78.12.6585-6594.2004

Lan, K., Kuppers, D. A., Verma, S. C., Sharma, N., Murakami, M., \& Robertson, E. S. (2005b). Induction of 
Kaposi's sarcoma-associated herpesvirus latency-associated nuclear antigen by the lytic transactivator RTA: a novel mechanism for establishment of latency. $J$ Virol, 79, 7453-7465. http://dx.doi.org/10.1128/JVI.79.12.7453-7465.2005

Lan, K, Verma, S. C, Murakami, M., Bajaj, B., \& Kaul, R., et al. (2007). Kaposi's sarcoma herpesvirus-encoded latency-associated nuclear antigen stabilizes intracellular activated Notch by targeting the Sel10 protein. Proc Natl Acad Sci USA, 104, 16287-16292. http://doi.org/10.1073/pnas.0703508104.

López-Ocejo, O., Viloria-Petit, A., Bequet-Romero, M., Mukhopadhyay, D., Rak, J., \& Kerbel, R. S. (2000). Oncogenes and tumor angiogenesis: the HPV-16 E6 oncoprotein activates the vascular endothelial growth factor (VEGF) gene promoter in a p53 independent manner. Oncogene, 19(40), 4611-20. http://dx.doi.org/10.1038/sj.onc.1203817

Maho, N., Takahiro, N., Chie, S., Tsutomu, I., Norihiko. Y., \& Shigeru, K. (2014). LRIG1 as a Potential Novel Marker for Neoplastic Transformation in Ocular Surface Squamous Neoplasia. PLoS One, 9(4), e93164. http://doi.org/10.1371/journal.pone.0093164.PMCID: PMC3977825.

Martha, T., Kenneth, S., Chikoti, M. W., Didintle, M., Hayley, G., Kathleen, A., .. Carrie, K. (2014). Oncogenic Viral Prevalence in Invasive Vulvar Cancer Specimens from HIV Positive and Negative Women in Botswana. Int J of Gyn Cancers. 24(4), 758-65. http://doi.org/10.1097/IGC.0000000000000111.

McDonnell, J. M., McDonnell, P. J., Mounts, P., Wu, T. C., \& Green, W. R. (1986). Demonstration of papillomavirus capsid antigen in human conjunctival neoplasia. Arch Ophthalmol, 104(12), 1801-5. http://dx.doi.org/10.1001/archopht.1986.01050240075043

Mindiola, R., Caulejas, D., Nunez-Troconis, J., Araujo, M., \& Delgado, M., et al. (2008). Increased number of IL-2, IL-2 receptor and IL-10 positive cells in premalignant lesions of the cervix. Invest Clin, 49, 533-545.

Moore, P. S., Boshoff, C., Weiss, R. A., \& Chang, Y. (1996). Molecular mimicry of human cytokine and cytokine response pathway genes by KSHV. Science, 274, 1739-1744. http://dx.doi.org/10.1126/science.274.5293.1739

Moore, P. S., \& Chang, Y. (1998). Antiviral activity of tumor-suppressor pathways: clues from molecular piracy by KSHV. Trends Genet, 14, 144-150. http://dx.doi.org/10.1016/S0168-9525(98)01408-5

Münger, K, \& Howley, P. M. (2002). Human papillomavirus immortalization and transformation functions. Virus Res., 89(2), 213-28. http://dx.doi.org/10.1016/S0168-1702(02)00190-9

O’Neil, J. D., Owen, T. J., Wood, V. H, Date, K. L, Valentine, R., Chukwuma, M. B., Arrand, J. R, Dawson, C. W, \& Young, L. S. (2008). Epstein-Barr virus-encoded EBNA1 modulates the AP-1 transcription factor pathway in nasopharyngeal carcinoma cells and enhances angiogenesis in vitro. J Gen Virol, 89(Pt 11), 2833-42. http://doi.org/10.1099/vir.0.2008/003392-0.

Parkin, D. M., Nambooze, S., Wabwire-Mangen, F., \& Wabinga, H. R. (2010). Changing cancer incidence in Kampala, Uganda, 1991-2006. Int J Cancer, 126(5), 1187-95. http://doi.org/10.1002/ijc.24838.

Parkin, D. M. (2006). The global health burden of infection-associated cancers in the year 2002. Int J Cancer, $118(12), 3030-44$.

Raab-Traub, N. (2002). Epstein-Barr virus in the pathogenesis of NPC. Semin Cancer Biol, 12, 431-441. http://dx.doi.org/10.1016/S1044579X0200086X

Ravi, R., Mookerjee, B., Bhujwalla, Z. M., Sutter, C. H., Artemov, D., Zeng, Q., Dillehay, L. E., Madan, A., \& Semenza, G. L. (2000). Bedi A. Regulation of tumor angiogenesis by p53-induced degradation of hypoxia-inducible factor 1alpha. Genes Dev., 14(1), 34-44. http://dx.doi.org/10.1002/ijc.21731

Risse Marsh BC, Massaro-Giordano M, Marshall CM, Lavker RM, Jensen PJ

Rosellini, A., Papini, S., Giannarini, C., Nardi, M., Revoltella, R. P. (2007). Human conjunctival epithelial precursor cells and their progeny in 3D organotypic culture., Int J Dev Biol. 51(8), 739-43. http://dx.doi.org/10.1387/ijdb.062198ar

Samanta, M., Iwakiri, D., \& Takada, K. (2008). Epstein-Barr virus-encoded small RNA induces IL-10 through RIG-I-mediated IRF-3 signaling. Oncogene, 27, 4150-4160. http://doi.org/10.1038/onc.2008.75.

Sarid R., Flore O., Bohenzky R. A., Chang Y., \& Moore P. S. (1998). Transcription mapping of the Kaposi's sarcoma-associated herpesvirus (human herpesvirus 8) genome in a body cavity-based lymphoma cell line (BC-1). J. Virol., 72, 1005-1012. 
Sherr, C. J., \& McCormick, F., (2002). The RB and p53 pathways in cancer. Cancer Cell., 2, 103-112. http://dx.doi.org/10.1016/S1535-6108(02)00102-2

Sinclair, A. J., Palmero, I., Peters, G., \& Farrell, P. J. (1994). EBNA-2 and EBNA-LP cooperate to cause G0 to G1 transition during immortalization of resting human B lymphocytes by Epstein-Barr virus. EMBO J., 13, 3321-3328.

Smith-McCune, K, Zhu, Y. H., Hanahan, D., Arbeit, J. (1997). Cross-species comparison of angiogenesis during the premalignant stages of squamous carcinogenesis in the human cervix and K14-HPV16 transgenic mice. Cancer Res., 57(7), 1294-300.

Tischer, E., Mitchell, R., Hartman, T., Silva, M., Gospodarowicz, D., Fiddes, J. C., \& Abraham, J. A. (1991). The human gene for vascular endothelial growth factor. Multiple protein forms are encoded through alternative exon splicing. J Biol Chem., 266(18), 11947-54.

Tornesello, M. L., Waddell, K. M., Duraturo, M. L., Biryahwaho, B., Downing, R., Lucas, S. B., Giani, U., Buonaguro, L., \& Buonaguro, F. M. (2005). TP53 codon 72 polymorphism and risk of conjunctival squamous cell carcinoma in Uganda. Cancer Detect Prev., 29(6), 501-8. http://dx.doi.org/10.1016/j.cdp.2005.08.003

Trends in cancer incidence in Kyadondo County, Uganda, (2000). Br J Cancer., 82(9), 1585-92.

Vajdic, C. M, van Leeuwen, M. T, McDonald, S. P, McCredie, M. R, Law, M., Chapman, J. R, Webster, A. C, Kaldor, J. M, Grulich, A. E. (2007). Increased incidence of squamous cell carcinoma of eye after kidney transplantation. $J$ Natl Cancer Inst., 99(17), 1340-2. Epub 2007 Aug 14. http://dx.doi.org/10.1093/jnci/djm085

Verma, S. C, Lan, K., \& Robertson, E. (2007). Structure and function of latency-associated nuclear antigen. Curr Top Microbiol Immunol, 312, 101-136. http://doi.org/ 10.1007/978-3-540-34344-8_4.

Verma, S. C., \& Robertson, E. S. (2004). Kaposi's sarcoma-associated herpesvirus-encoded latency-associated nuclear antigen inhibits lytic replication by targeting Rta: a potential mechanism for virus-mediated control of latency. J Virol., 78, 6585-6594. http://dx.doi.org/10.1128/JVI.78.12.6585-6594.2004

Vikhanskaya, F., Bani, M. R, Borsotti, P., Ghilardi, C., Ceruti, R., Ghisleni, G., Marabese, M., Giavazzi, R., Broggini, M., \& Taraboletti, G. (2001). Overexpression increases VEGF and reduces thrombospondin-1 production: implications for tumor angiogenesis. Oncogene, 20(50), 7293-300. http://dx.doi.org/10.1038/sj.onc.1204896

Waddell, K. M., Downing, R. G., Lucas, S. B., \& Newton. R. (2006). Corneo-conjunctival carcinoma in Uganda. Eye (Lond). 20(8), 893-9. http://dx.doi.org/10.1038/sj.eye.6702043

Woodworth, C. D., McMullin, E., Iglesias, M., \& Plowman, G. D. (1995). Interleukin 1 alpha and tumor necrosis factor alpha stimulate autocrine amphiregulin expression and proliferation of human papillomavirus-immortalized and carcinoma-derived cervical epithelial cells. Proc Natl Acad Sci USA, 92, 2840-2844. http://dx.doi.org/10.1073/pnas.92.7.2840

Yoshizaki, T., Horikawa, T., Qin-Chun, R., Wakisaka, N., Takeshita, H., Sheen, T. S., Lee, S. Y., Sato, H., \& Furukawa, M. (2001). Induction of interleukin-8 by Epstein-Barr virus latent membrane protein-1 and its correlation to angiogenesis in nasopharyngeal carcinoma. Clin Cancer Res, 7, 1946-1951

Zacny, V. L., Wilson, J., Pagano, J. S. (1998). The Epstein-Barr virus immediate-early gene product, BRLF1, interacts with the retinoblastoma protein during the viral lytic cycle. J. Virol., 72, 8043-8051.

Zhang, Q., Gutsch, D., \& Kenney, S. (1994). Functional and physical interaction between p53 and BZLF1: implications for Epstein-Barr latency. Mol. Cell. Biol., 14, 1929-1938. http://dx.doi.org/10.1128/MCB.14.3.1929

\section{Copyrights}

Copyright for this article is retained by the author(s), with first publication rights granted to the journal.

This is an open-access article distributed under the terms and conditions of the Creative Commons Attribution license (http://creativecommons.org/licenses/by/4.0/). 